\title{
The Action of Cold and of Sunlight upon Aquatic Plants.
}

BY

ALFRED J. EWART, D.Sc, PH.D., F.L.S.

N a recent paper by Messrs. West and West, these authors 1 take exception to certain results published by me two years ago in my first paper upon Assimilatory Inhibition ${ }^{1}$. The objections which they make form an admirable illustration of the mistake into which biologists and collectors often fall in making use, or rather misuse, of experimental observations made by the physiologist in the laboratory. The prejudice which seems to exist in certain quarters against the results of laboratory investigations is an extremely absurd and unreasonable one, for it is only by research of this kind that any accurate and precise knowledge of fundamental principles can be obtained. The conditions under which plants exist in nature are so variable and complicated that it is impossible by direct observation to determine precisely what are the factors engaged in producing any given result, especially since any marked change in the external conditions must necessarily affect not merely one, but directly or indirectly every form of vital activity of which the plant is capable. It is true that particular

1 West and West, Ann. of Bot., I896, Vol. xii, p. 33 ; Ewart, Journ. Linn. Soc. Bot., Vol. xxxi, I896, p. 2 I 7 .

[Annals of Botany, Vo1. XII. No. XIVII. September, I898.] 
influences may directly affect single functions only or these in more marked degree than in others, but in every case, even if only a single function is directly affected, an indirect effect must finally be produced upon all the other functions, provided the stimulus affecting the first function acts for a sufficiently long period of time. This is a necessary corollary to the intimate connexions and correlations which exist in the living organism between its different functional activities.

In laboratory experimentation we make use of these principles, the effects produced on single functions being noted in plants kept under otherwise normal conditions, while at the same time the direct and indirect effects produced are as far as possible distinguished from one another. Having obtained a knowledge of the action of the different factors constituting the external world upon each particular vital function, the next thing necessary is to submit the results thus obtained to the test of nature, by which they must stand or fall. If, however, the observations made in nature do not coincide with the results obtained by laboratory experiment, it does not necessarily follow that either are incorrect. The discrepancy between the two may simply indicate that in either or both cases certain operating factors have not been noticed or allowed for.

It is therefore as absurd for the biologist to deride the results obtained by laboratory experimentation, as it would be for the physiologist to disregard the criticisms and limitations which the biologist imposes upon him. Only by giving to each their proper value and importance can the facts observed by the biologist and physiologist be correlated and brought into harmony with one another ${ }^{1}$.

Bearing these facts in mind, I proceed to discuss certain points in the paper by Messrs. West, to which the above disquisition appears to be especially applicable. In the

\footnotetext{
1 An admirable general account of these and similar questions is given in the introduction to Pfeffer's new Pflanzenphysiologie. (An English translation is in process of preparation for the Clarendon Press.)
} 
first place, Messrs. West are able, by citing a fragmentary sentence from my paper on Assimilatory Inhibition, to quote on my apparent authority the statement that no fresh-water Algae are resistant to cold, and that all are killed by being frozen. It is perhaps hardly necessary to mention the fact that the statement made was expressly intended to refer only to those Algae actually examined. These were extremely few in number, for the above research was conducted solely in order to determine the influence of various normal and abnormal injurious agencies upon the function of $\mathrm{C} \mathrm{O}_{2}$-assimilation. Moreover, for this very reason, the plants employed were such as were in an actively vegetating condition, and which had been grown or had been kept for some time previously under optimal conditions of temperature, \&c. It is well known that many plants can be gradually accustomed to low temperatures (or other injurious agencies) to which, when suddenly exposed, they inevitably succumb. Frequent reference is made to this long-known and frequently studied peculiarity throughout the work mentioned and in subsequent ones also. In the work first published, the only fresh-water Algae examined with regard to the effects of cold upon them were undetermined species belonging to the genera Oedogonium and Spirogyra, and two to that of Cladophora. To have founded any general conclusions as to the resistant powers to cold of the great group of fresh-water Algae upon such isolated observations as these, would indeed have been somewhat premature. It is however certain that many, or perhaps very many or all, of the higher filamentous fresh-water Algae, and perhaps of other aquatic plants as well, are exceedingly sensitive, when in the actively vegetating condition, to temperatures approaching to or falling but little beneath the freezing-point. A few observations recently made may be of interest here, for they illustrate more precisely what the resistant powers to cold of such plants actually are. In all cases the plants employed were actively vegetating, and had been kept at a temperature of from $15^{\circ}$ to $20^{\circ} \mathrm{C}$. for 
some time. That Spirogyra is very sensitive to cold is quite certain. Thus a sample of class-material composed of $S$. crassa and $S$. nitida was killed in a single night, owing to the temperature accidentally being allowed to fall from about $20^{\circ} \mathrm{C}$. to just below zero, and that although no actual ice-crystals were formed in the water in which the plants lay. Similarly with actively vegetating specimens of Spirogyra nitida, S. crassa, S. flavescens, Vaucheria sessilis, $V$. terrestris, and of Nitella, all the vegetative parts were killed by exposure during a single night to a temperature not falling below $-2^{\circ}$ to $-3^{\circ} \mathrm{C}$, which caused a partial conversion only of the surrounding water into ice. After freezing for one night at from $-2^{\circ} \mathrm{C}$. to $-5^{\circ} \mathrm{C}$., Vallisneria spiralis, Cladophora, and Chara were entirely killed; in Elodea canadensis occasional living cells were still to be found; Lemna minor and Lemna trisulca were partially killed; while of Diatoms and Desmids, very many of the Desmids Euastrum and Closterium were killed, and many of the Diatoms Navicula and Pinmularia. After being frozen at $-8^{\circ} \mathrm{C}$. to $-10^{\circ} \mathrm{C}$. for several hours by means of a freezing mixture of ice and salt, Lemna minor and Lemna trisulca were killed, as well as both the Diatoms and Desmids. In the former, as is usually the case, the chlorophyll bodies were broken up and disorganized. In the latter the 'Endochrome' was also disorganized and frequently shrunken, while no plasmolysability could be detected in any of the cells. When, however, the cultures were returned to normal conditions, after two weeks or so, living Diatoms of the same kind reappeared, but no Desmids. In the former case apparently a few resistant forms had remained living and escaped observation. This might possibly have occurred with the Desmids also had these previously formed any resistant spores.

Of several Oscillarias examined, all remained living, though in some cases the filaments were in part killed. Similarly in Gloeocapsa, Scenedesmus, and Protococcus most or almost all of the cells remained living, whereas the zoospores of Protococcus (Chlamydococcus?) were dead and non-motile when 
thawed out ${ }^{1}$. It is interesting to notice that, when in the motile condition, organisms appear to be more sensitive to cold (and to other injurious agencies as well) than when in the non-motile resting or vegetating condition. This may be partly due to the protecting cell-wall being thin or absent in the motile condition, partly to the more highly developed functional activities and special irritabilities which the motile zoospore possesses. In the motile and highly irritable condition the plant is able to avoid injurious agencies to a greater extent than it can when in the nonmotile or fixed condition, and hence, in the former case, a development of high resistant powers is less necessary; for the motile stages are, as a general rule, of only short duration, and are produced only when the external conditions are favourable.

Even in multicellular plants, the protoplasts of which are always clothed with a cell-wall, an increased motility of the plasma seems to go hand in hand with a decreased resistant power to cold. In certain cases, at any rate, an increase in the amount of water present in the cell or cell-plasma accompanies this increased motility. This is the case, for example, in the rotating cells of Chara and Nitella, in the staminal hairs of Tradescantia, and in the parenchyma of the leaf and stem, and in the epidermal cells of Elodea canadensis and Vallisneria spiralis, in which various stimuli readily induce rotation. For in all these cases streaming movements appear only as the amount of water present in the cell increases, and the most active rotation is shown only when a single large central vacuole is present. No cell, the protoplasm of which shows active streaming movements or rotation, appears to be able to withstand either freezing or desiccation ${ }^{2}$.

From the observations made by Messrs. West upon the survival of certain forms in frozen pools from year to year,

${ }_{1}^{1}$ Zoospores of Ulothrix and Haematococcus can continue to move at $0^{\circ} \mathrm{C}$.

${ }^{2}$ See Assim. Inhib., Journ. Linn. Soc. Bot., Vol. xxxi, p. 394; also Trans. Liverpool Biol. Soc., I897, p. I57. 
although no formation of zygospores was observed in them, no precise conclusions can be drawn. It is sufficient to recall how frequently the existence of special reproductive organs in fresh-water and marine Algae has been overlooked by a series of investigators to make certain how unreliable any such negative observations are, however carefully conducted they may be. The most painstaking and conscientious investigator would shrink from the task of subjecting to thorough and systematic microscopical examination the entire contents of even a small pond filled with vegetable life, and yet, as is well known, the existence of only a few zygospores might cause, under renewed favourable conditions, the original vegetation to be restored in a comparatively short period of time. Moreover, a formation of asexual aplanospores or of resting-cells might escape observation with even greater readiness. That, however, the zygospores, aplanospores, and resting-cells may remain dormant for prolonged periods of time is well known, and that they can resist considerable extremes of temperature, such as would be immediately fatal to the plants when in the actively vegetating condition, is extremely probable, and indeed almost certain from the observations which Messrs. West record. It must, however, always be remembered that at the bottom of the pond, in the mud, \&c., in which the spores lie, the temperature is not necessarily and indeed is rarely the same as it is on the frozen surface.

Nor does it follow that plants imbedded in ice or covered by snow are frozen. Both snow and ice are very bad conductors of heat, and therefore, as is well known, a layer of snow acts as a protective mantle to the plants which it covers. Living plants have a power of producing heat which may be so marked, when no transpiration is going on, as to raise their temperature several degrees above that of the surrounding medium. Beneath the snow, however, this factor hardly comes into play, since at low temperatures the vital activities of even the most resistant plants are reduced to a minimum or to nil, and it is upon the con- 
tinuance of these vital activities that the production of heat depends. Thus cell-division ceases to take place at zero or a few degrees above it ${ }^{1} ; \mathrm{CO}_{2}$-assimilation ceases in tropical plants between $4^{\circ} \mathrm{C}$. and $8^{\circ} \mathrm{C}$, in warm, temperate, sub-tropical and water-plants between $0^{\circ} \mathrm{C}$. and $2^{\circ} \mathrm{C}$., while in cool, temperate, arctic and alpine plants assimilation only ceases when the plants are frozen, i.e., at a few degrees below zero ${ }^{2}$. Similarly rotation gradually diminishes as the temperature falls below the optimum, and after remaining for a prolonged period at a temperature at or near zero may cease, temporarily or permanently ${ }^{3}$, while faint respiration may go on even below zero until a temperature of $-10^{\circ} \mathrm{C}$. is reached ${ }^{4}$. It is evident that even when a plant is surrounded by a medium the temperature of which is several degrees below zero, since faint respiration may, in very resistant plants (many Conifers, Mosses, Lichens, Schizophyta, and unicellular Algae), still continue, the interior of a morphological or accidental cell-aggregate may be at a slightly higher temperature, provided the loss of heat by conduction, radiation, or transpiration is slight or absent. Though a trifling, this is by no means a negligible quantity, and may, since the production of heat goes on continually, be one of considerable importance, when all transpiration is prevented and the plant is frozen in ice and surrounded by an insulating jacket of air, or is covered by snow. Freshwater plants, especially if massed together, are frequently found to be covered by bubbles of gas when the water in which they lie freezes. Moreover, the water around the plant may be melted or absorbed so that the bubbles coalesce, and the plant or portions of it come to lie in insulating air chambers, which form an admirable protection from the outside cold. In such a chamber, when exposed to ordinary light, the heat-rays which penetrate the ice will

\footnotetext{
' Strasburger, Zellbildung und Zelltheilung, I880, p. I I I.

${ }^{2}$ Ewart, Assim. Inhib., Journ. Linn. Soc. Bot., Vol. xxxi, p. 401.

${ }^{3}$ Cf. Ewart, 1. c., p. 394.

${ }^{4}$ Jumelle, Rev. Gén. de Bot., Vol. iv, I892, p. I 4 seq.
} 
be collected and concentrated upon the plant by the concave walls of the chamber in which it lies, and thus may keep the temperature of the plant from falling below its own special freezing-point during the daytime. The chlorophyll, along with the water, \&c., which the plant contains, forms a very efficient warmth absorbing agency. It is probably by means of the heat thus directly absorbed that the ice immediately surrounding a frozen plant may be melted, even when exposed only to the relatively feeble rays of the wintry sun. I have frequently found the vegetative shoots of Elodea enclosed in ice in this manner, and have seen in some cases that the stem and most of the leaves were in part or entirely living, although the vegetative shoots of this plant are always infallibly killed when properly frozen. In plants covered by not more than two or three centimetres of snow, radiation from above cannot supply any appreciable amount of heat to the plant, owing to the relatively high opacity of loose or freshly fallen snow when in mass both to radiant light and heat. Nor can any noticeable amount of heat be derived by the plant under these circumstances by radiation or conduction from beneath. The special efficiency of snow as a protective agency seems to be simply due to the fact that the mixture of air and ice of which it is composed forms an admirable insulating medium so long as the temperature remains low, while at the same time the loss of heat by transpiration or by radiation is reduced to nil or to a minimum.

The case mentioned by Messrs. West, in which filaments of Spirogyra were found, when thawed out from the ice in which they had been frozen for some time, to be in conjugation, and that nevertheless the vitality of the filaments was unimpaired, is hardly applicable to the point at issue, and moreover, involves two contradictory statements. Surely in the process of conjugation the vitality of the flament is always impaired, for with the completion of the process the further existence of the filament ceases. Each zygospore is a new organism, and possesses very different resistant 
powers from those of the vegetative filament which produced it. It contains much less water than the cells of the vegetative filament do, and its powers of resistance to desiccation and freezing are correspondingly increased. As is well known, unfavourable conditions generally tend to induce conjugation. Thus, plants of Spirogyra may be caused to conjugate by allowing the water in which they are kept to very gradually evaporate. Hence conjugation may, in many cases at any rate, be regarded as a sign that the external conditions have become unfavourable in some respect, and that the plant is endeavouring by those means to tide over the unfavourable period. This action of unfavourable external conditions in inducing a formation of zygospores is strictly comparable with the effects which partial starvation or an unfavourable habitat may exert upon many higher plants, causing them to run more rapidly to seed, and thus hastening their own exhaustion.

No haphazard observations in which the period and conditions of exposure can only be approximately estimated can afford any decisive evidence in dealing with even the simplest problems of this kind. When a perennial land-plant is subjected to gradually increasing cold, as, for example, at the onset of winter, it commonly prepares itself in a variety of ways for the increased cold which may be expected to follow. In addition to the immediately obvious external changes, certain important internal changes also take place. Thus the starch in the bark, \&c., of Phanerogamic trees and shrubs, as Fischer and others ${ }^{1}$ have shown, and in the leaves of evergreens as well, according to Lidforss, may be converted into sugar in cold winters, and be retained as such, dissolved in the cell-sap, while starch-grains reappear, after a more or less prolonged latent period, when the plant is brought into a warm room. By the above means the concentration of the cell-sap is markedly increased, so that the freezing-

1 Fischer, Beiträge zur Physiologie der Holzgewächse, Pringsh. Jahrbücher, Bd. xxii., Heft I, pp. 73-160: Bengt Lidforss, Zur Physiologie und Biologie der wintergrünen Flora, Bot. Ct.-Bl., Bd. lxviii, I896, p. 34. 
point of the plant as a whole is lowered, and it is enabled to withstand cold, to which, if suddenly exposed in summer, it would have been more sensitive, and by which it might have been killed.

Similarly water-plants may undergo preparatory modifications when winter is approaching. Thus in Elodea the vegetative shoots die down, while from the rhizomic stems buried in mud arise condensed etiolated shoots, the cells of which are packed with starch-grains in November. Later still this starch may partially or entirely disappear, being gradually converted into sugar as the cold becomes more intense. In such mud the plants are well protected, for the water it contains may not freeze until the temperature falls several degrees below zero; and moreover the chemical changes and decompositions which continue to go on to a certain extent in organic mud, even at low temperatures, may produce a slight but by no means negligible quantity of heat, and a correspondingly higher temperature. Ordinary turgid plant-cells do not begin to freeze until the temperature falls from two to four degrees below zero. As ice-crystals form and water is extracted, the freezing-point for the more concentrated watery solution remaining is correspondingly lowered. Moreover, the freezing-point for capillary imbibed water undergoes an even more marked depression, for, as Dixon and Joly ${ }^{1}$ have shown, the imbibed water in the walls of wood vessels does not freeze until a temperature of $-10^{\circ} \mathrm{C}$. or $-\mathrm{II}^{\circ} \mathrm{C}$. is reached. Hence it is only when the temperature is at least as low as this that the plant is completely frozen, though it commences to freeze at two or three degrees below the freezing-point for distilled water.

The statement, therefore, that no purely aquatic fresh-water Alga, or, indeed, that no purely aquatic fresh-water plant, can withstand complete freezing when in the actively vegetating condition is one which, though sufficient evidence is not yet at hand to establish the generality of its application, will

1 Dixon and Joly, Ann. of Bot., I895, Bd. ix, p. 4 I6. 
almost certainly be corroborated by the necessary experimental research. All plants growing entirely submerged in fresh water must be always in a condition of maximal turgidity, and contain the full amount of water possible. As is well known, it is those parts which are richest in water which are first affected by cold, and are most readily injured by being frozen. It does not, however, necessarily follow that a tissue rich in water will be killed by being frozen, as is shown by the high resistant powers exhibited by the leaves of Sempervivum, Sedzm, \&c., and by many Mosses as well ${ }^{1}$.

With regard to amphibious plants, i.e. plants which (I) grow partly in and partly out of the water, or (2) float upon its surface, or (3) may lead either a submerged or a subaerial existence, these seem to have acquired more marked resistant powers than are possessed by plants growing always completely submerged in fresh water. This is only natural and to be expected, considering the variable conditions under which such plants live and the exposure to which they may be subjected; but even then comparatively few, excepting Schizophytes, such as the Cyanophyceae and Bacteria, seem able to withstand complete freezing when in the actively vegetating condition. That the plants of the first class die down at the approach of winter is familiar to all, though in cases where the water remains comparatively warm throughout the winter, the submerged leaves may remain living and green, and even form starch. Of the second class Lemna affords a good example, as also do the floating leaves of Water-lilies, \&c. That the leaves of Water-lilies are killed by being completely frozen is a matter of common observation. Lemna appears able to withstand partial freezing, especially in the younger parts, but all vegetative parts are killed by being completely frozen.

The third class includes all forms which can grow indifferently in water, or upon mud, damp soil, or other

${ }^{1}$ See Assim. Inhib., Journ. Linn. Soc. Bot., Vol. xxxi, I896, p. 389 .

$\mathrm{C} \mathrm{C}$ 
substrata. It therefore embraces Pleurococcus, Scenedesmus, Protococcus and allied forms, Schizophytes such as the Cyanophyceae and Bacteria, and such plants as Vaucheria, Mucor, \&c. It is in this group that the forms most resistant to cold are met with, though all grades of resistant powers are shown. In this connexion it is important to notice the relationship which exists between resistance to desiccation and resistance to freezing. All plants or parts of plants which can withstand desiccation can also withstand freezing ${ }^{1}$, though many plants which can be frozen and yet remain living cannot be fully desiccated or even completely air-dried without being killed. Thus Schröder ${ }^{2}$ found that the leaves of Echeveria secunda began to die on losing from 50 to 60 per cent. of the water normally present, and died on losing 60 to 80 per cent. Sedum elegans gave similar results, but was able to withstand more complete desiccation. These plants and Sempervivum also can, however, survive exposure even to comparatively severe cold $^{3}$. The reason for this difference appears to be that freezing involves a less complete and perfect withdrawal of water from the living cell and cell-plasma than desiccation does, and that on thawing the water is immediately available for reabsorption, whereas in desiccated specimens it is removed not merely from the cell, but away from the plant entirely. It is with regard to the capillary imbibed water that the difference between freezing and desiccation is probably especially manifest. By complete desiccation, not only all free water, but also very nearly the whole of the capillary imbibed water, may be removed; and only certain seeds, Mosses, Bacteria, \&c., can withstand desiccation reducing the amount of water present to as low as from $I$ to 2 per cent. When a moist plant is frozen, however, the capillary imbibed water

\footnotetext{
${ }^{1}$ See Assim. Inhib., Journ. Linn. Soc. Bot., Vol. xxxi, I896, pp. 374-402 ; and Power of withstanding Desiccation in Plants, Trans. Liverpool Biol. Soc., Vol. xi, I 897 , p. I 5 I.

2 Bot. Unters. Tübingen, Bd. ii, Heft I, I886, p. 5.

3 See Assim. Inhib., I896, 1. c., p. 389 .
} 
does not apparently begin to freeze until the temperature approaches or falls below $-10^{\circ} \mathrm{C}$. The water occupying the centre of the micellar canals or interstices of an organized structure will be the first to freeze. The film of water or layer of water-molecules directly abutting upon the walls of the micellar canals and coming within the sphere of the molecular influences radiating from the molecules, molecular complexes, or micellae composing these walls, will be restrained with even greater force from assuming the molecular arrangement and character constituting the solid condition. The amount of such water is, however, relatively trifling, and being firmly retained can hardly be made use of in metabolism when no other supply of water is available. It is possible, therefore, to make the dogmatic statement that no manifestation of vital activity can take place at a temperature below $-10 \mathrm{C}$. to $-12^{\circ} \mathrm{C}$. Jumelle has already been shown to be in error in supposing that $\mathrm{CO}_{2}$-assimilation could continue at temperatures as low as $-30^{\circ} \mathrm{C}$. to $-40^{\circ} \mathrm{C}$. ${ }^{1}$ It is, however, in all cases safe to conclude that plants which can withstand complete desiccation cannot be killed by cold. This has been shown to be the case with several of the more resistant Bacteria and bacterial spores by the researches of Dewar and McKendrick, as well as by other investigators, while Chodat ${ }^{2}$ has shown that the spores of Mucor mucedo survive exposure to from $-70^{\circ} \mathrm{C}$. to $-110^{\circ} \mathrm{C}$. for two hours ${ }^{3}$. Similarly many Palmellaceae, Cyanophyceae, \&c., can withstand prolonged desiccation over sulphuric acid, and, as has already been shown, complete freezing also, even when in the vegetative condition. Such are Haematococcus phuvialis, Pleurococcus vulgaris, Pleurococcus miniatus, Rhaphidium polymorphum, Gloeocapsa, Merispomedia, Nostoc commune, Oscillaria antliaria, O. temuis and $O$. subfusca. On the other hand, Confervae, Haematococcus nivalis, the zoospores of

${ }^{1}$ See Assim. Inhib., 1. c., p. 402.

${ }^{2}$ Chodat, Bulletin Herb. Boissier, 1896, p. 870.

${ }^{3}$ Brown and Escombe subjected a variety of air-dried seeds to a temperature of $-183^{\circ} \mathrm{C}$. to $-192^{\circ} \mathrm{C}$. for $\mathrm{I}$ Io hours, and found that their germinative power was not perceptibly affected. (Proc. Roy. Soc., 1xii, I897, p. I60.)

$$
\text { C C } 2
$$


Protococcus pluvialis, Oscillaria sancta, and vegetative Diatoms and Desmids are killed by air-drying and also by being completely frozen. The zygospores of Zygnema can, however, withstand several years' air-drying, and are therefore hardly likely to be affected by cold ${ }^{1}$. The filaments of Vaucheria and the normal vegetative mycelia of Penicillium, Mucor, and Physomyces are killed by drying and also by being completely frozen at $-10^{\circ} \mathrm{C}$. to $-12^{\circ} \mathrm{C}$. In Mucor and Penicillium the mycelia may be made more resistant by growing them on concentrated nutrient solutions, while in the form of Mucor yeast, the resistant powers are very different from those of the normal vegetative Mucor mycelium ${ }^{2}$.

With regard to marine Algae, many of these are, as the researches of Kjellmann upon the Arctic Flora have shown, very resistant to cold, and it is possible, and indeed probable, that as a class they are more resistant to cold than those fresh-water Algae are, which are purely aquatic. According to $\mathrm{Pfeffer}{ }^{3}$, in sea-weeds the internal isosmotic force which the cell-sap exerts must be greater than in land-plants, and also than in fresh-water plants, for the former are frequently subjected to great external pressure and are also surrounded by a weak saline solution, and yet the phenomena of turgidity which they present are in general similar to those exhibited by land or fresh-water plants. Hence, in seaweeds the cellsap will be more highly isosmotic, or more highly concentrated than in fresh-water plants, and therefore a lower temperature will be required to completely freeze the former than the latter. Similarly, just as in Penicillium, where the adaptation to growth in concentrated solutions causes an increased

1 See Schröder, Bot. Unters. Tübingen, Bd.i, Heft I, I886; Ewart, Assim. Inhib., I 895 , l. c., p. 375 , \&c.

${ }_{2}$ Chodat, 1. c., supposes that spores of Mucor mucedo which had commenced to germinate might nevertheless resist exposure to $-70^{\circ} \mathrm{C}$., but the details of his experiments do not support this conclusion, and it is certain from my own observations that the young vegetative mycelium of Mucor is killed by several hours' exposure at a temperature of from $-\mathrm{IO}$ to $-\mathrm{I} 2^{\circ} \mathrm{C}$., although if any acrospores or endospores have been formed, these will germinate and produce new mycelia when restored to a normal temperature.

3 Pflanzenphysiologie, 2. Aufl, Bd. i, sec. 24. 
resistant power to freezing and dessication to be developed, so also may the accommodation to a marine habitat induce a correspondingly greater resistant power in plants which have been gradually transferred from the one medium to the other. Kjellmann has indeed observed that arctic marine Algae may continue to grow and even flourish at or even below zero centigrade, a power which no fresh-water Alga is known to possess. We have apparently here to do with an adaptive modification of similar character, but taking place in the reverse direction to that occurring in those Oscillatorias which can grow and flourish in hot springs.

Similarly with regard to those plants which constitute the Flora of the regions of perpetual snow, we find that these are plants which exhibit special adaptive modifications suiting them to their peculiar habitat. It must be remembered that in such regions the snow is commonly extremely hard and compact, and that the surface is usually more or less dirty and covered with dust fallen from the air, along with numerous micro-organisms which find here conditions suitable for their development. When exposed to direct sunlight, the insolationtemperature will be relatively extremely high for all absorbent bodies which are not cooled by radiation, conduction, or evaporation, whereas at night the temperature falls many degrees below zero. Since the snow reflects so much light and absorbs so little, it follows that coloured microscopic organisms may be at a temperature many degrees above zero when exposed to sunlight, although the snow on which they lie shows no immediate signs of melting. Even in gullies or hollows, sheltered from the sun, the amount of radiated heat which reaches the organisms may suffice to keep them unfrozen during the day, although the snow always remains perfectly hard. When the sun is shining upon them, alpine plants are exposed to extremely intense illumination, such as many plants are unable to withstand. Hence a protective red pigment is often found in the microscopical snoworganisms which contain chlorophyll. This pigment absorbs as much as possible of those rays which exercise an injurious 
effect upon the chloroplastids and also upon the cell-plasma, and which are least useful in $\mathrm{CO}_{2}$-assimilation ${ }^{1}$.

The plants which compose a snow-flora must be able to withstand sudden and marked extremes of temperature. They must be able to have all or almost all of the water which they contain removed or converted into solid form without being killed, and must be capable of an almost immediate resumption of both respiration and assimilation when the water is restored, either directly when the plant is dry or by thawing when it is frozen. If any prolonged latent period of recovery always followed as a necessary consequence after short but severe exposure, the plant would waste most of the precious day-time exposure in recovering and preparing for the full resumption of all its vital activities when returned to more favourable conditions. It has already been shown that exceedingly resistant plants do actually exist, which even after prolonged air drying or exposure to severe cold remain living, and almost instantaneously recommence to assimilate and respire, when the temperature is raised to the optimum, and the normal water percentage restored ${ }^{2}$.

Lagerheim found that the flora of the perpetual snow region of Pichincha was composed of four species of Chlamydomonas (Volvocineae), Glococapsa, Nostoc, Navicula, Glococystis, Rhaphidonema nivale (Ulothrix form), and also a saprophytic fungus, Selenotila nivalis, in all twenty-one species. In Vallidal, Swedish Lapland, Wittrock found about nine species of Desmids. Altogether the known snow-flora comprises about seventy species ${ }^{3}$. Wittrock (1.c., pp. 86, 120) finds that the zygospores of the snow Volvocineae (Chlamydomonas) and also the resting-stages (non-motile vegetative condition) can withstand air drying. The same has been shown to be

1 Ann. of Bot. Vol. xi, 1897, Sept., p. 477 .

${ }^{2}$ Assim. Inhib., l. c., pp. $3_{5}^{8}, 3^{89}$. (Mosses, Lichens, Protophyta.)

${ }^{3}$ Lagerheim, Die Schneeflora des Pichincha, Ber. d. Bot. Gesell., I892, Bd. x, p. 5 I 7 ; V. B. Wittrock, Om Snöns och isens flora, särskeldt i. de arktiska traktema. Stockholm, ז883. 
the case in Gloeocapsa, Nostoc, Glococystis, \&c. These plants can therefore also resist great extremes of cold. Navicula and other Diatoms do not appear when in the vegetative condition to be so resistant, and actively vegetating Desmids are still less resistant. As regards Selenotila and Rhaphidonema, no data are at present available.

The observations recorded by Messrs. West (1. c., p. 35) that plants of Closterium striolatum and Cylindrocystis Brebissonii were found growing in the water derived from melting snow at a (probable) temperature of $\mathrm{I}^{\circ} \mathrm{C}$. to $2^{\circ} \mathrm{C}$. is interesting but not surprising, and has moreover but little scientific value, since the actual temperature of the water was not determined.

With regard to the effects of direct sunlight upon freshwater Algae, Messrs. West have apparently here fallen into the error of supposing that because the surface of a shallow pond is exposed to direct sunlight, that therefore the plants growing in it are exposed to the same intensity of sunlight as well (1. c., pp. 35 and 36). It is perhaps hardly necessary to mention the fact that unless the sun is directly overhead, a larger or smaller percentage of the incident rays fail to penetrate the water, which is an optically denser medium, and at the surface of which both refraction and reflection take place. As is well known, when the incident angle is an acute one, a very large part of the light, or almost the whole of it, may be reflected without penetrating below the surface; and since the shadow of a landscape upon a still surface of water may appear on a photographic plate to have almost the same intensity as the original picture, it follows that the more refrangible rays with which we are immediately concerned must be reflected in as great if not greater amount than the less refrangible rays are. The oblique light-rays which actually penetrate are bent towards the perpendicular, and hence traverse a shorter distance to reach the bottom of a pond. This may be of considerable importance in the sea by enabling oblique light-rays to penetrate to a greater depth, and thus allow the marine 
flora to extend into deeper water than it otherwise could; but in a shallow exposed pond it may occasionally cause a dangerously intense perpendicular illumination to be still further prolonged. Moreover, ordinary pond-water teeming with living and dead particles is only semi-transparent, while, as has in various places been shown ${ }^{1}$, an apparently trifling protection-such as a sheet of oiled tissue-paper, or the inclination of the leaf obliquely or parallel to the incident rays, afford-may suffice to adequately shield the sensitive tissues or organs from any injurious effects which prolonged and continuous exposure to direct sunlight might have produced.

When a mass of green Algae has been floating on the surface of a pond exposed to direct sunlight, frequently the uppermost filaments may be entirely or largely bleached, and either still living or dead ${ }^{2}$. Whether this takes place or not, the filaments beneath will always be subjected to a very much diminished intensity of illumination. There can hardly be any doubt but that in an ordinary pond, even when comparatively shallow, the brighter the sunlight, and the more there is of it, the more active will be the growth of the vegetation in the pond as a whole. This is, however, simply because then the average amount of light which the vegetation as a whole receives, approaches nearer to, but does not surpass, the optimal intensity for continued assimilation. The very air or oxygen bubbles, with which an assimilating filament may become covered, cut off from it a certain amount of the light which would otherwise reach it. For all these reasons, when the illumination is comparatively weak, green organisms can develop on the surface only.

When, however, exposure to bright light induces a formation

1 Assim. Inhib., 1. c., I 895 and I 896 ; Ann. of Bot. Vol. xi, Sept., I 897 .

${ }^{2}$ Partially bleached filaments of Spirogyra may remain living for a considerable time, and may show a feeble evolution of oxygen from the entire chlorophyll band or from parts of it only. If the bleaching is at all marked, a regeneration of chlorophyll is possible only in the young cells. 
of zygospores (West, 1.c., p. $3^{6}$ ), it does so probably because it is acting injuriously upon the vegetative filaments, for conjugation appears to be induced in Conjugatae, when the external or internal conditions are becoming unfavourable in some way or other. That conjugation might exercise an after stimulating effect upon neighbouring non-conjugating cells, arousing them to increased vegetative activity, is not impossible, provided that plasmatic connexions existed, or that a plasmatic transference were proved to take place through the partition-walls of neighbouring cells of the same filament. This has not yet, however, been demonstrated in these plants, and the occurrence of lateral conjugation by special conjugating tubes connecting neighbouring cells of the same filaments renders the existence of any such interprotoplasmic communication extremely improbable. Physiologically, each adult cell of a Spirogyra-filament appears to be a distinct individual. The fact that when conjugation takes place, the activity of the neighbouring cells appears also to be increased, may simply indicate that the same causes which are inducing conjugation in certain cells are stimulating others to an increased vital activity manifested in other ways. Recent research has shown that injuries and injurious agencies generally, if not too severe, may cause an increased respiration, an increased production of heat, a commencement or increase in the rapidity of rotation, and generally may cause a more marked and active conversion of potential energy into kinetic, while upon the primary processes of constructive metabolism, at any rate as regards $\mathrm{CO}_{2}$-assimilation, the reverse effect is produced ${ }^{1}$. In many cases the energy liberated is partially expressed in the form of an increased growth activity, precise determinations of which have been given by Townsend and the writer in certain special cases ${ }^{2}$. An increased katabolism, however, involves

${ }^{1}$ Richards, Ann. of Bot, Vol. x, I896, p. 53I, Vol. xi, March, 1897, p. 29 ; Ewart, Ann. of Bot., Vol. xi, Sept., 1897, p. 447, \&c.

2 Townsend, Ann. of Bot., 1897, p. 509; Ewart, Ann. du Jard. bot. de Buitenzorg, 1898 , Vol. xv, p. 198 , \&c. 
a greater production of waste katabolic products, some of which (organic acids and their salts) are highly osmotically active. An increased turgidity is therefore to be expected in such cells, other factors remaining constant, and provided that the substances used up in katabolism are either replaced, or are not at all or only slightly osmotically active. It is perhaps in this way and by the softening of the cell-wall at certain points, that the fertilization-tubes are produced in Spirogyra. The subsequent contraction of the protoplasts before actual conjugation takes place might be either an active or a passive one, the water filtering out under marked pressure in the first case or slight in the second. If the contraction of the stretched protoplast is a passive one, then either the plasmatic membrane must have become more permeable, or else the osmotic concentration of the inclosed cell-sap must have undergone a rapid and marked diminution. That the latter is possible and even probable is shown by the fact that in the formation of the zygote a marked conversion of osmotic substances into non-osmotic ones takes place (sugars, \&c., into oil, starch, \&c.). In this way a rapid lowering of the internal osmotic pressure might be produced previously to conjugation. In any case the result is the same, a very resistant body, the zygote, being finally produced, which is very well adapted to withstand desiccation, extreme cold, \&c.

From all the facts mentioned above, it is easy to see that only by means of laboratory investigations, in which the experiments are performed under otherwise constant conditions, can any precise conclusions be arrived at with regard to complicated vital phenomena, nor is any determination of the resistant powers of a plant to any given agency possible, unless all other external agencies or modifying factors are allowed for, removed, or kept constant.

That intense illumination acts injuriously upon all exposed living parts of plants is now quite certain, as may be seen by reference to various sources, commencing with Pringsheim's 
classical researches, and ending with the observations made by the writer ${ }^{1}$.

The same injurious action of intense light is produced upon all plants, whether with or without chlorophyll, though in chlorophyllous cells it is almost always the chlorophyllgrains which are first affected ${ }^{2}$. Thus both non-chromogenic and chromogenic Bacteria, including those which contain chlorophyll and grow normally only when exposed to diffused daylight, may be killed by prolonged exposure to direct sunlight, and even the vitality of the spores may be fatally affected by somewhat more prolonged exposure ${ }^{3}$. It is for this reason that the spores of Mosses, Ferns, \&c., and the pollen-grains of higher plants, are covered by comparatively opaque external coverings, for in order that the full effect of the sunlight may be produced, it must penetrate with undiminished intensity to the living contents of the cell.

It is extremely improbable that any living protoplast if naked, or if enclosed by a transparent wall, could withstand exposure to the full and undiminished intensity of sunlight for even a day (twelve hours' constant exposure), and certainly not when exposed successively day after day. In a chlorophyllous cell it is the chlorophyll-grains which are first affected. The reason for this is that these are organs specially adapted for collecting and intercepting sunlight. Light-rays, which pass unaltered directly through the cell, cannot possibly exert any effect upon it. It is only the rays which are altered in their passage through, or actually absorbed, which can exert any influence upon the living plasma or plasmatic plastids. Hence it is upon the chlorophyll-bodies that the most marked effect is produced by intense illumination ${ }^{4}$. It is important to remember in this

1. Assim. Inhib., Journ. Linn. Soc., Vol, xxxi, pp. 439, 443, 573; Ann. of Bot., Sept., I 897 , Vol. xi, p. 339; Pringsheim, Pringsh. Jahrb., Bd. xii, I882, pp. 326, 345 ; the literature quoted in these works.

${ }^{2}$ Journ. Linn. Soc., Vol. xxxi, p. 573 (Chara); Ann. of Bot., l. c.

${ }^{3}$ See Frankland and Ward, Report of Thames Water Commission; Ward, Annals of Botany, March, I898, Vol. xii (A Violet Bacillus), p. 65.

${ }_{4}^{4}$ Assim. Inhib., Journ. Linn. Soc, Vol. xxxi, I896, p. 573, \&c. 
connexion that a substance transparent to the eye may be opaque to particular rays, and that a colourless tissue may reflect or absorb a considerable portion of the light falling upon it.

The effect produced upon the chloroplastids is not, however, directly proportional to the total amount of light which they absorb, for it is the blue-violet rays which produce the greatest photo-chemical effect, whereas the chlorophyllous absorption in this region of the spectrum is not nearly as great as it is in the red.

The following experiments illustrate these points more clearly, and give more precise data concerning the duration as well as the intensity of the exposure which chloroplastids can successfully withstand. Perfectly accurate data could be obtained only by experimenting with a constant source of illumination, the intensity of which could be varied at will, for when sunlight is used its intensity may continually alter during the exposure. Hence in the following experiments the sunlight was concentrated and the exposure correspondingly shortened, while by using single cells or unilamellar cell-aggregates the intensity of light which reaches the chloroplastids is but little diminished. End-cells of Chara foetida and the laminar portions of the leaves of Elodea were therefore exposed in water to the sun's rays, concentrated by means of an ordinary concave mirror, and previously cooled by passing through a cold solution of alum.

The image of the sun thrown at the level of the microscope stage was rather less than $\frac{1}{80}$ th of the area of the reflecting mirror, but the photo-chemical intensity (for silver salts) of the concentrated sunlight was much less than it should theoretically have been, namely 25 to 30 times greater than that of the direct sunlight, or after passing through an alum solution only 8 to ro times greater. The intensity of the light employed is indicated by the terms $4 \mathrm{~S}, 6 \mathrm{~S}, 8 \mathrm{~S}$, \&c., where $S$ represents the full intensity of the strongest sunlight.

Elodea canadensis, leaf-cells exposed in water, cooled by evaporation and with plenty of oxygen. 
I. 5 minutes' exposure to about $6 \mathrm{~S}$; chloroplastids pale greenish yellow, rotation absent or very slow, and in ro min. more rapid, but occasional cells die and rotation ceases. After I hour tested with bacteria, weak power of assimilation, absent or doubtful in parts ${ }^{1}$.

2. Cell showing one rotation per $25 \mathrm{sec}$. after $2 \frac{1}{2} \mathrm{~min}$. in $5 \mathrm{~S}$, rotation slows to $55-60 \mathrm{sec}$. per revolution 2-3 min. after exposure ; then in $5 \mathrm{~min}$. begins to quicken, and in $10 \mathrm{~min} .=35 \mathrm{sec}$. per revolution, in $20 \mathrm{sec}$. original rate. Chloroplastids slightly paler.

3. No alum-solution, I min. exposure stops active rotation, chloroplastids quite green. After I hour still no rotation, but apparently a weak evolution of oxygen; but careful examination shows that the movement of the bacteria continues in the darkness, and that many semi-anacrobic bacteria are present, and are attracted by the nutritious fluids evolved from the dying cells. Using bacteria from a young and well-aerated culture, no evolution of oxygen can be detected, and after 5 hours cells are no longer plasmolysable and replasmolysable.

4. (a) With alum-solution, light $=4 \mathrm{~S}$; after I $5_{5}$ min. exposure chloroplastids partially bleached, feeble rotation, which become active after $\frac{1}{4}$ hour in weak light.

(b) Light $=4$ to $6 \mathrm{~S}$; after $\mathbf{5}$ min. rotation almost ceased, begins to recover in $5 \mathrm{~min}$., and is quite active again in $\mathbf{I}_{5}$. Chloroplastids more or less bleached.

(c) Closed-cell-preparation. Owing to increased heating effect rotation ceases in nearly all cells after $5 \mathrm{~min}$, recovering again in $5^{-1} 5$ min. if only a part of the leaf was exposed. After ro min. exposure, permanent stoppage, cells die, but the chloroplastids are not bleached (deficient supply of oxygen).

5. (a) Light $=8 \mathrm{~S}$, rotation ceases in 5-6 min., chloroplastids quite pale, and in 6-8 min. quite colourless, no recovery. After 5 min. exposure the cells mostly recover, rotation recommences in $\frac{1}{4}$ to I hour, and after being in diffuse light for $2-3$ days paler exposed patch can no longer be distinguished from rest of leaf.

(b) Without alum-solution, rotation ceases in $3^{-4} \mathrm{~min}$., chloroplastids still yellowish green, recovery in many cases but not in all.

1 Longitudinal strips are most suitable for examination. The Bacteria were obtained from well aerated putrescent fluids (See Kny, Ber. d. D. Bot. Ges. xv, $\mathrm{I} 897, \mathrm{p} .388$ ), but the utmost caution is necessary with such impure cultures, and were it not that the results here given are simply confirmatory of previous ones, no mention would be made of them. 
In Chara foetida about io minutes' exposure to cooled and concentrated light ( 8 to $\mathrm{IOS}$ ) is sufficient to completely bleach a naked and non-encrusted end-cell. The chloroplastids on the under surface bleach first, those on the upper at the same time or immediately afterwards, and those at the sides a minute or two later. If the exposure and bleaching are localized, the cell may remain living, and the majority of the bleached chloroplastids retain their original position, so that, although a few come free and are carried away by the rotating plasma, no naked areas are formed, as was the case in Pringsheim's experiments ${ }^{1}$. The rotating plasma experiences a certain check at the exposed area, and finally the current may cross the cell at this point and return up the other side, the endoplasm being thus divided into two distinct rotating masses. Such cells always die when returned to normal conditions. By suddenly exposing preparations of end-cells of Chara to light, it is easy to show that the bleached portions have no power of evolving oxygen by $\mathrm{CO}_{2}$-assimilation; and when such end-cells are kept in $2 \%$ glycerine, starch-grains are formed in the green chloroplastids, but not in the colourless ones, which have therefore not only lost the power of $\mathrm{CO}_{2}$-assimilation, but also of starch formation.

Similar results were obtained with leaf-cells of Elodea, and although it has not been found possible to entirely bleach all the chloroplastids of a cell without killing the latter, still living cells may be obtained in which a portion of the chloroplastids are entirely bleached, and the rest are pale yellow to yellowish green. The latter may become normally green again, and are able to form starch, whereas however long the leaves may be kept in a $5 \%$ sugar-solution, no starch-grains appear in the bleached chloroplastids. Living end-cells of Chara have been observed in which the bleached chloroplastids were retained for an entire year without undergoing any further change ${ }^{2}$, and hence apparently light not only kills and bleaches the chloroplastids, but also converts its proteid

${ }^{1}$ Pringsheim, Pringsh. Jahrb., Bd. xii, r882, pp. 326-344.

2 Journ. Linn. Soc., I897, Vol. xxxi, p. 573. 
substance into some extremely insoluble modification. It is possible to completely bleach all the chloroplastids of a leaf-cell of Elodea without previously active rotation entirely ceasing, and when returned to normal conditions rotation may become active again in a quarter to half-an-hour. All such cells die in water in a day or two, though they may be kept for as long as a week in dilute sugar or glycerine.

A few experiments were also made upon a couple of chlorophyllous animals, Hydra viridis, with definite 'chloroplastids,' and Vorticella campanula, with diffuse chlorophyll.

Vorticella campanula. I. Light $=4-5 \mathrm{~S}$, killed in I min. in closed cell preparation without any perceptible bleaching of the chlorophyll. In an open drop of water the animals are killed (no alum-solution) in 3-4 min., but behind an alum-solution 5-6 min. are required, and in this time the chlorophyll is almost completely bleached. The contractions and expansions take place more slowly in 2-3 min., and finally the stalk may remain contracted, and the body contracted or expanded in light rigor. Partial recovery may take place, a portion of the cilia commencing to move again. A weaker intensity of light may at first accelerate movement, the contractions and re-expansions of the stalk taking place at shorter intervals.

2. Secondary effect of light. After exposure to the brightest diffuse daylight for I day, almost all the Vorticella zooids separate from their stalks and become free swimming. This is probably an attempt to escape an unfavourable intensity of light.

3. 8-10 S, movement almost immediately ceases, recommencing in I-5 min., according to the length of the (non-fatal) exposure. Temporary light-rigor if suddenly induced may leave the stalks and bodies more or less completely expanded, and on removing the light the first movement may be to complete the previously commenced coiling. If the light-rigor is at all prolonged $(2-3 \mathrm{~min}$.), death immediately follows.

Hydra viridis. I. Exposed to $6 \mathrm{~S}$, at once retracts, and remains so till death occurs. Ends of tentacles bleached in 10 min., body still dark green after I 5 min., but power of recovery is lost. It is possible to permanently destroy the motility of some of the tentacles by localized exposure, while the rest remain living. After Io min. exposure tentacles may be killed, but the body may show feeble 
contractions and expansions $\frac{\mathbf{1}}{2}$.hour afterwards, stronger after $\mathbf{I}$ hour, but permanently ceasing after 5 hours.

2. 8-ro S, after $5 \mathrm{~min}$. animals killed, body greenish yellow, tentacles bleached. With shorter exposure temporary light-rigor may be produced in some of the tentacles, and by localized exposure the middle of the animal's body may be killed and contracted, while the base and apex remain living for several hours, and capable of responding to light, \&c. Hydrae, in which the body is still greenish and capable of expanding and contracting, may show no perceptible evolution of oxygen when exposed to light.

It appears therefore as if the plasma of a chlorophyllous animal is more sensitive to light than that of a plant such as Chara, for the animal is killed before the chlorophyll is bleached, whereas almost the whole of the chloroplastids may be bleached without producing any permanent injury upon the rest of the cell ${ }^{1}$. This is well illustrated in the following comparative experiments, in which the light concentrated, after passing through an alum-solution, had a photo-chemical intensity ten times greater than that of the strongest direct sunlight.

Elodea canadensis. After $5 \mathrm{~min}$. all exposed cells bleached and killed. If the end of a cell is exposed, only the chloroplastids stationary here bleach, and such cells may show rotation extending up to the bleached part but not into it, while cells at the margin of the exposed area with green chloroplastids may show variations and changes in the direction of the rotation, or the chlorophyll-grains may be aggregated into a rotating ball at one end of the cell, or rotation may even be shown in cells with partially retracted contents.

Chara foetida. Complete bleaching requires nearly $8 \mathrm{~min}$. exposure. After $\frac{1}{2}$ min. rotation may be twice as rapid, but in $4-5$ min. slows rapidly, is very slow by the time the chloroplastids are bleached, and may gradually stop after the exposure has ceased, but in other cases may recover again. When the entire cell is exposed, complete bleaching almost always involves the rapid or immediate death of the cell.

1 The bleaching of the chloroplastids is an oxidatory process, and less oxygen may reach the chlorophyll in an animal's body than in a plant-cell. 
Hydra viridis. The animals instantly retract, and after 3-4 min. projecting parts of tentacles slightly bleached, body quite dark green. Recovery is possible, and after $\frac{1}{2}$ hour partial expansions and contractions, more active after $\mathrm{I}$ hour. After $5^{-6} \mathrm{~min}$. exposure the animals are killed, but hardly at all bleached.

Vorticella campanula. 3-4 min. causes complete bleaching, but the animals may be fatally affected a minute sooner than this.

Streptococcus varians ${ }^{1}$. Thick turbid culture of this green bacterium was entirely decolourized by 5 hours' exposure to direct sunlight, though the bacteria reappeared again later.

The independence of rotation and $\mathrm{CO}_{2}$-assimilation, and the fact that assimilatory inhibition is not necessarily dependent upon the destruction of the chlorophyll, have already been established. Chloroplastids of Chara rotating in the endoplasm are shielded from the light by the outer chloroplastids, and may remain green after the exoplasmic layer has been completely bleached. In Elodea, however, the chloroplastids all assume the apostrophic position, and rotating corpuscles are exposed to the same or an even greater intensity of light than outer stationary ones; but nevertheless the former are less rapidly affected than the latter, probably because the exposure is more evenly distributed as the rotating chlorophyll-corpuscle turns over from time to time. As the rotation slows, the chloroplastids may distribute themselves to a greater or less extent over the cell, and both these factors aid somewhat in producing more rapid bleaching. In all cases the bleaching apparently takes place with markedly increasing rapidity towards the end of the exposure as the chloroplastids become fatally affected. Thus with an intensity of light sufficient to completely bleach the chloroplastids in six minutes, during the first four minutes but little change in colour may be apparent, while during the fifth minute the corpuscle becomes much paler green, and during the sixth minute all green colour is lost. If we assume that the decomposition and reconstruction of chloro-

${ }^{1}$ Journ. Linn. Soc., Vol. xxxiii, I897, p. I 5 o.

D d 
phyll proceed simultaneously in every chloroplastid exposed to light, and that the former process is more rapid than the latter when the light is strong, then the apparently more rapid bleaching at the end of the exposure might be due to the reformation of chlorophyll having ceased to take place, and this would indicate that fresh chlorophyll can normally be produced with great rapidity, though not much more rapidly than the chloroplastids of Spirogyra can form starch ${ }^{1}$. It is, however, extremely difficult to estimate changes of coloration by comparison with the surrounding chloroplastids so long as the exposed ones are distinctly green, and the same loss of chlorophyll which converts a pale green chloroplastid into a colourless one may cause no perceptible difference in the coloration of a dark green one. As a matter of fact, the leaves of many plants may yield a much weaker extract of chlorophyll after a day's exposure to strong light than is obtained from a similar bulk of shaded leaves, although the eye may be unable to detect any difference in the depth of coloration of the two sets of leaves, and hence it is doubtful whether the apparently more rapid decomposition of chlorophyll as the chloroplastids become fatally affected is not simply an optical delusion.

Assuming that this peculiarity does actually exist and cannot be entirely explained by the facts already given, it might be possible that the chlorophyll, when in organic connexion with a living plastid, is more resistant to the oxidatory photo-chemical action of sunlight than it is when isolated, or when the organic union is disturbed or destroyed. If plants of Elodea are killed by chloroform, and exposed in well-aerated water to the action of bright light for a day, including nearly three hours' intermittent sunlight, all the exposed leaves are completely bleached, whereas a normal healthy plant subjected to the same exposure retains a healthy green colour, though perhaps slightly paler.

\footnotetext{
${ }^{1}$ G. Kraus, Jahrb. f. Wiss. Bot., I869-7o, Bd. vii, p. 5 II.
} 
Similarly living plants remain a normal green in bright diffuse daylight, whereas dead ones are bleached in a couple of days in the presence of oxygen, although if placed in well-boiled water, covered by a layer of oil, they retain their green colour for an almost indefinite length of time. Unless we admit that the decomposition and the reformation of chlorophyll proceed simultaneously when the living chloroplastid is exposed to light, the above facts can only be explained by assuming that in the living chloroplastid the chlorophyll is held in some such manner as to render it resistant to the action of light, and that it is only when released from this vital combination that it can be oxidized and decomposed.

Chlorophyllous cells, however, suddenly killed by chloroform, and exposed to intense light as soon as the chloroform has evaporated, take from $2-3$ times as long to bleach as living ones do. In such dead cells the plasma is slightly more opaque, but on the other hand the slightly bluish green dead chloroplastids are distributed evenly throughout the cell, and are hence exposed to a slightly greater average intensity of light on this account. Living chloroplastids may at first evolve oxygen, and hence help to bleach themselves, but this certainly ceases long before the bleaching is complete. If a closed-cell-preparation of a leaf of Elodea, which has been kept in darkness for some time to remove all free oxygen, is suddenly exposed to cooled and 10 times concentrated sunlight, the leaf-cells are killed without any perceptible bleaching of the chlorophyll having taken place, and hence it is evident that in such intense light $\mathrm{CO}_{2}$-assimilation ceases almost immediately, if any is ever possible. Similarly if a leaf of Elodea is passed through chloroform, a condition of anaesthesia may be induced which lasts for five or ten minutes, or even longer. Rotation ceases, the chloroplastids distribute themselves regularly over the cell, the power of response to external stimuli is temporarily in abeyance, and from the results given later it is also certain that the power of $\mathrm{CO}_{2}$-assimilation is temporarily lost. Such D d 2 
cells take only a minute or two longer to bleach than normal living ones do. Hence it appears that the difference is due to the fact that in the dead cell light exercises a photochemical action upon a dead inert substance, whereas in the living cell it acts upon a working vital mechanism composed of substances which are continually undergoing change, and causes katabolic and oxidatory changes to preponderate over the anabolic ones. (It must be remembered that there is no necessary connexion between the bleaching of the chlorophyll and the death of the chloroplastid, and it may be found possible, under certain circumstances, to completely bleach chloroplastids without killing them. As a matter of fact, cases have been observed in Elodea in which the chloroplastids were almost entirely bleached, but yet remained living and capable of recovery.

Even assuming that the rate at which the chlorophyll is decomposed in the presence of oxygen is directly proportionate to the intensity of the light, it does not necessarily follow that in unconcentrated sunlight decomposition is also more active in the living chloroplastids than it is in dead ones. A living end-cell of Chara is, however, bleached by 6-8 hours' exposure to continuous sunlight $(6-7$ minutes when exposed to sunlight 10 times concentrated), whereas an end-cell killed by chloroform is bleached under similar conditions in about 2 hours, but when exposed to ro times concentrated sunlight I2-I5 minutes' exposure is required. It seems therefore justifiable to conclude that during the period of exposure to direct sunlight the living chloroplastids had formed at least five times as much chlorophyll as they originally contained. Without attaching too much importance to these calculations, they are nevertheless interesting as showing the perpetual change to which the living chloroplastid is subject when exposed to light. Under prolonged exposure to the same intensity of sunlight, old chlorophyllous cells bleach much more rapidly than young but fully grown cells do; whereas in concentrated sunlight, in which the bleaching is produced in a few minutes, no marked 
difference is perceptible. This is evidently due to the fact that the reconstruction of chlorophyll is more active in the younger chloroplastids, and it is easy to see why chlorophyllous organs, when the sunlight is discontinuous, may be able to withstand a far greater total exposure than when it is continuous.

It is of considerable interest to know whether there is a certain maximal intensity of light beyond which $\mathrm{CO}_{2-}$ assimilation immediately ceases to be possible, so that momentary exposure to such light acts just as momentary darkness does, causing assimilation to cease until normal conditions of illumination are restored. Intense illumination, however, soon puts the assimilatory mechanism out of order, and hence a direct stoppage of $\mathrm{CO}_{2}$-assimilation is possible without the chloroplastids being markedly affected, only when the exposure is extremely brief. The following experiments were all performed with cooled and 10 times concentrated sunlight. The bacterium-method is not directly applicable, for any Bacteria which come within the circle of intense light are at once rendered immotile, and moreover a closedcell-preparation must be employed. After 5 minutes' exposure in a drop of water the power of assimilation is lost by the exposed parts of an Elodea leaf, and may either not return, or, if the chloroplastids are still green, recovery may take place in one hour to a day. In a closed-cellpreparation, rotation may be stopped and may never recommence if the entire leaf has been exposed, the leaf-cells dying of asphyxia in 2-3 hours, whereas if oxygen is admitted, rotation recommences and the cells may remain living. The chloroplastids have therefore temporarily or permanently lost the power of producing oxygen ; for in a normal closedcell-preparation exposed to light of moderate intensity, the oxygen evolved by $\mathrm{CO}_{2}$-assimilation suffices to maintain active rotation, the latter ceasing after IO-I 5 minutes' darkness, and recommencing within a minute in the light, though it does not become fully active until several minutes have elapsed. 
If a leaf of Elodea is exposed to light in water containing carbonic acid, minute bubbles of gas ooze out from the ends of the interspaces in the leaf ${ }^{1}$, but when exposed to concentrated light, this ceases almost at once, and instead water may be sucked in, either owing to the cessation of $\mathrm{CO}_{2}$ assimilation, or to the increased oxidatory activity consuming all the oxygen that would otherwise have been set free. Reinke $^{2}$ found that Elodea gave off gas-bubbles most actively in direct sunlight, the activity being unchanged even when the light was 60 times concentrated, and the evolution of gas-bubbles diminished only when the plants were injuriously affected by a much greater intensity of light than this. The intensity of the light falling upon the outside of a glass vessel is, however, much greater than that which penetrates the living cells, and the optimal and maximal light-intensities for $\mathrm{CO}_{2}$-assimilation are not those which fall upon the outside of the plant, but those which reach and react upon the chloroplastids. There is good reason to suppose that in all cases the optimal light-intensity for contimued $\mathrm{CO}_{2}$-assimilation in the chloroplastid is less than that of direct sunlight. When plants are exposed to intense sunlight in water, the rapid rise in temperature causes the intercellular air to expand, and may appreciably affect the rate at which gas-bubbles are evolved; and it is possible, by rapidly warming the water in which recently killed plants lie, to produce a slight evolution of bubbles from the cut end of the stem, just as if feeble $\mathrm{CO}_{2}$-assimilation had taken place ${ }^{3}$. Hence it is doubtful whether the evolution of gas-bubbles noticed by Reinke from plants exposed to 60 times concentrated sunlight was actually due to any $\mathrm{CO}_{2}$-assimilation taking place at this intensity of illumination.

It appears therefore that in living chloroplastids exposed to light, the decomposition and reconstruction of chlorophyll proceed simultaneously, and that in certain cases the total

1 Cf. Kohl, Ber. d. Bot. Ges., I897, Bd. xv, p. I 20.

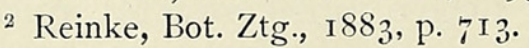

3 See note on Chloroform anaesthetization, infica, p. $4^{\mathrm{I}} 5$. 
amount formed in a single day may be several times greater than that present at any given moment. Light acts both as a stimulus to the formation of chlorophyll, and at the same time induces its photo-chemical oxidation. The former is a vital action, and is by no means directly proportional to the intensity of the illumination, for ordinary diffuse light appears to afford the optimal stimulus to chlorophyll formation. The decomposing action of light is, however, directly proportional to its photo-chemical intensity, if an abundant supply of oxygen be present. Hence in strong light the decomposition of chlorophyll preponderates, and it is easy to understand why an etiolated plant turns green more rapidly in diffuse daylight than in direct sunlight. The inhibitory effect exercised by strong light upon the assimilatory powers of the chloroplastids is not necessarily the result of a diminution in the amount of chlorophyll which they contain, but may be due to some break having occurred in the chain of processes which constitute $\mathrm{CO}_{2}$-assimilation, or perhaps to the necessary vital connexion between the plasma and the newlyformed chlorophyll not being properly established. It is, however, inadvisable to push these theoretical conclusions too far, nor do these experiments afford any support to Pringsheim's ingenious hypothesis as to the protective function of chlorophyll.

The purpose of my own experiments has throughout been to determine how long the living chlorophyll-grains in the intact cell can withstand exposure to direct sunlight, and what length of time elapses before their functional activity is perceptibly affected. Hence when compound tissues, composed of several layers and covered by an epidermis, were employed, the light was frequently concentrated by mirrors, or with more sensitive leaves these were simply kept exposed to perpendicular illumination for prolonged periods; while when water-plants, \&c., were employed, care was taken that the full intensity of the illumination actually reached the living contents of the cells.

Once the intensity of the illumination has been deter- 
mined, beyond which any increase in the light reaching the living cells injuriously affects them, it is possible to calculate the intensity of the illumination to which the plant as a whole may in nature be exposed without any particular cells forming part of it being directly injured, provided the amount lost by the absorption and reflection of the interposed protecting layers, \&c., is known. For an account of the adaptive modifications shown by the tropical plants, and the means by which those growing in exposed situations are able to protect themselves from the effects of over-exposure, reference may be made to the paper on the effects of tropical insolation ${ }^{1}$.

Here; except where otherwise mentioned, the thermal and photo-chemical effects were allowed to act together, but even then it was found that the leaves of most of the plants examined were resistant to even prolonged exposure to continuous direct sunlight, although slight injurious effects might be produced upon them. Naturally, if but one surface is directly exposed, only the cells immediately beneath this surface become perceptibly affected. By using a mirror, however, the under surface of the leaf may be illuminated as well, and the cells in the interior subjected to an intensity of illumination approaching more closely to that of direct sunlight. Many shade-plants are comparatively sensitive to prolonged exposure to direct sunlight. Thus the chlorophyllgrains of Pisonia alba, Selaginella sp.(?), Chara hispida, Spirogyra crassa, \&c., may be almost or entirely bleached by a single day's exposure, and although they have temporarily lost the power of assimilation, on returning to normal conditions they may become green and commence to assimilate again in a few days (1. c., pp. 442, 443). Trans-

${ }^{1}$ Ann. of Bot., Sept., 1897, Vol. xi, p. 339. Giltay (Annales du Jardin Bot. de Buitenzorg, 1898 , Vol. $x v$, p. 68) has shown that Cassia timorensis in diffuse daylight assimilates $6.4 \mathrm{mg}$. $\mathrm{CO}_{2}$ per $\frac{1}{2}$ sq. m. of leaf, but when exposed to strong sunlight only $5 \cdot 7 \mathrm{mg}$. $\mathrm{CO}_{2}$, owing to the erect position which the leaflets assume, and hence owing to this protective adaptation the optimal intensity of illumination for the assimilation of the plant as a whole is markedly reduced. 
piration keeps thin exposed leaves cool so long as an adequate supply of water is available, but in many fleshy leaves this is not the case, and the effect produced upon the power of $\mathrm{CO}_{2}$-assimilation may be largely a thermal one, for the temperature of such leaves, when isolated, may amount to as much as $50^{\circ} \mathrm{C}$. (1. c., p. 444). When at the same time any discoloration is produced in the chlorophyll-bodies, the leaves, instead of being blanched, turn brown or yellow (1. c., Vanilla, Hoya, Cocculus Beccarii), and it is curious that the action of light, combined with low temperatures, may cause a similar browning ${ }^{1}$. Thus at ordinary temperatures the photo-chemical action of light causes a blanching of the chloroplastid, whereas at extremes of temperature a browning may be produced, if the leaves remain living for a sufficient length of time under such exposure. In the majority of cases, however, healthy and normal leaves are comparatively resistant to prolonged exposure to direct perpendicular sunlight, even when the under surface is also illuminated, no perceptible effect being produced, or only a slight one in the surface layers immediately exposed. Often, however, in such apparently normal leaves, the assimilatory powers may be markedly affected, in parts or entirely. It is important to remember that in a condition of nature, so long as the temperature remains normal, it is very rarely indeed that the exposure is sufficiently intense or prolonged to produce any of the results which may be obtained under the much severer experimental conditions. As soon, however, as precise experimental data are obtained, it is easy to determine the amount of external exposure which any given plant can withstand in a condition of nature, knowing the conditions under which it exists and the protective adaptations which it possesses.

${ }^{1}$ Winter browning of Conifers, \&c., Journ. of Linn. Soc., Vol. xxxi, p. 390.

BOtANicAl Laboratory, OXFORD. 


\section{$2 \mathrm{BHL}$ Biodiversity Heritage Library}

Ewart, Alfred J. 1898. "The action of cold and of sunlight upon aquatic plants." Annals of botany 12, 363-397.

https://doi.org/10.1093/oxfordjournals.aob.a088699.

View This Item Online: https://www.biodiversitylibrary.org/item/233102

DOI: https://doi.org/10.1093/oxfordjournals.aob.a088699

Permalink: https://www.biodiversitylibrary.org/partpdf/318511

\section{Holding Institution}

Smithsonian Libraries

\section{Sponsored by}

Biodiversity Heritage Library

\section{Copyright \& Reuse}

Copyright Status: Not in copyright. The BHL knows of no copyright restrictions on this item.

This document was created from content at the Biodiversity Heritage Library, the world's largest open access digital library for biodiversity literature and archives. Visit BHL at https://www.biodiversitylibrary.org. 